\title{
Belgeo
}

Revue belge de géographie

$4 \mid 2005$

Miscellaneous

\section{Arlaud S., Jean Y. \& Royoux D., Rural-Urbain : Nouveaux liens, nouvelles frontières}

Rennes, Presses Universitaires de Rennes, 2005, 506 p.

Julien Vandeburie

\section{CpenEdition}

\section{Journals}

Édition électronique

URL : http://journals.openedition.org/belgeo/12218

DOI : $10.4000 /$ belgeo. 12218

ISSN : 2294-9135

\section{Éditeur :}

National Committee of Geography of Belgium, Société Royale Belge de Géographie

Édition imprimée

Date de publication : 31 décembre 2005

Pagination : 519

ISSN : 1377-2368

Référence électronique

Julien Vandeburie, «Arlaud S., Jean Y. \& Royoux D., Rural-Urbain : Nouveaux liens, nouvelles frontières », Belgeo [En ligne], 4 | 2005, mis en ligne le 29 octobre 2013, consulté le 22 septembre 2020. URL: http://journals.openedition.org/belgeo/12218; DOI : https://doi.org/10.4000/belgeo.12218

Ce document a été généré automatiquement le 22 septembre 2020

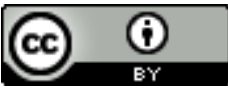

Belgeo est mis à disposition selon les termes de la licence Creative Commons Attribution 4.0 International. 


\title{
Arlaud S., Jean Y. \& Royoux D., Rural-Urbain : Nouveaux liens, nouvelles frontières
}

Rennes, Presses Universitaires de Rennes, 2005, 506 p.

\author{
Julien Vandeburie
}

\section{RÉFÉRENCE}

Arlaud S., Jean Y. \& Royoux D., Rural-Urbain : Nouveaux liens, nouvelles frontières, Rennes, Presses Universitaires de Rennes, 506 p.

1 Cet ouvrage est issu d'un colloque, il rassemble en trente-cinq chapitres des communications allant des réflexions géographiques à propos des espaces ruraux et urbains (avec entre autres, C. Alvergne, M. Vanier), aux représentations de ces espaces (M. Bussi et al., C. Beauchemin) en passant par les mutations des espaces périurbains (J.P. Hermia et al., G. Di Méo), les mutations des activités (A. Berger et P. Chevalier) et les questions de mobilité (C. Vignal).

2 Comme souvent dans ce type d'ouvrage, la qualité des communications est inégale. Néanmoins, J.-P. Hermia, T. Eggerickx et J.-P. Sanderson captent l'attention à propos des «Frontières et fragmentation démographique de l'espace périurbain bruxellois » (pp. 123-136). L'analyse montre de façon claire et concise les différents comportements des migrants de 3 couronnes de la périurbanisation bruxelloise. Mettant en relief le phénomène dans les dynamiques marquant la société belge, l'article est agréable à lire.

Une autre contribution digne d'intérêt est celle de M. Bussi, C. Colange, J. Fourquet, F. Girault et L. Ravenel sur la géographie électorale française (pp. 395-414). Si l'on déplore la qualité graphique des cartes (une faiblesse générale de l'ouvrage), on apprécie la qualité des recherches menées pour montrer les tenants de la géographie électorale. L'analyse des clivages, les croisements avec les enquêtes donnent d'intéressants résultats issus des différentes définitions du rural et de l'urbain usitées. Et de citer les 
auteurs «Le vote apparaît comme un excellent indicateur des modificateurs socioéconomiques des frontières rurales-urbaines ». 